\title{
Antalya bölgesi sulama şebekelerinin değerlendirilmesi
}

\section{Evaluation of the irrigation schemes in the Antalya region}

\author{
Sinan KARTAL ${ }^{1}$, Hasan DEĞİRMENCİ \\ ${ }^{1}$ Alanya Alaaddin Keykubat Üniversitesi, Gazipaşa MRB Meslek Yüksekokulu, Bitkisel ve Hayvansal Üretim Bölümü, Gazipaşa/ANTALYA \\ ${ }^{2}$ Kahramanmaraş Sütçü İmam Üniversitesi, Ziraat Fakültesi, Biyosistem Mühendisliği Bölümü, Kahramanmaraş
}

Sorumlu yazar (Corresponding author): S. Kartal, e-posta (e-mail): sinan.kartal@alanya.edu.tr

Yazar(lar) e-posta (Author e-mail): hdegirmenci46@gmail.com

\section{MAKALE BILGGISI}

Alınış tarihi 13 Mart 2020

Düzeltilme tarihi 16 Haziran 2020

Kabul tarihi 07 Temmuz 2020

\section{Anahtar Kelimeler:}

Sulama performans1

Kalite indeksi

Sulama şebekesi

Sulama oranı

\begin{abstract}
ÖZ
Bu çalışmada, Antalya bölgesinde bulunan 13 sulama şebekesi 2006-2016 yıllarına ait 11 yıllık veriler ile değerlendirilmiştir. Çalışmada su dağıtım, finansal ve tarımsal etkinlik göstergeleri kullanılmıştır. Sulama şebekelerinin performanslarının belirlenmesi ve karşılaştırılmasında korelasyon analizi, temel bileşenler analizi yapılıış ve sulama şebekelerinin kalite indeksleri belirlenmiştir. Yapılan performans değerlendirilmesinde her bir göstergeye ait 11 yıllık veri kullanılarak ortalama ve standart sapma değerleri hesaplanmıştır. $\mathrm{Bu}$ verilere göre sulama oranı en yüksek \%82.21 ile Korkuteli sulamasında, birim sulanan alana dağıtılan toplam sulama suyu miktarı en düşük $5532.32 \mathrm{~m}^{3} \mathrm{ha}^{-1}$ ile Mursal sulamasında bulunmuştur. Su temin oranı 3.74 ile en yüksek Alara sulamasında, fayda masraf oranı 0.76 olarak en düşük Manavgat sulamasında, birim sulanan alan üretim değeri $1855.53 \$$ ha $^{-1}$ ile en yüksek Çıplaklı sulamasında gerçekleşmiştir. Birim şebekeye alınan sulama suyu üretim değeri en yüksek $2.90 \$ \mathrm{~m}^{-3}$ ile Ciplaklı sulamasında hesaplanmıștır. Tüm performans göstergeleri faktör analizi kullanılarak tek bir sayıya (kalite indeksi değeri) indirgenmiştir. $\mathrm{Bu}$ indekse göre sulama şebekeleri, başarı sıralamasına tabi tutulmuştur. Yapılan kalite indeksi sıralamasında Korkuteli sulamas1 1523.91 ile ilk sırada yer alırken Manavgat sulamas1 -514.38 ile son sırada yer almıştır. Araştırma sonucunda sulama şebekelerinin başarısına en fazla tarımsal etkinlik göstergelerinin etkili olduğu görülmüştür.
\end{abstract}

\section{ARTICLE INFO}

Received 13 March 2020

Received in revised form 16 June 2020 Accepted 07 July 2020

\section{Keywords:}

Irrigation performance

Quality index

Irrigation schemes

Irrigation ratio

\section{ABSTRACT}

In this study, 13 irrigation schemes in the Antalya region were evaluated based on 11 years of data between the years 2006-2016. Water distribution, financial and agricultural efficiency performance indicators were used in the study. Correlation analysis and principal components analysis were performed, and quality indexes were calculated to evaluate and compare the performances of the irrigation schemes. Basic statistics of performance indicators' average values and standard deviations were calculated for the study period. According to results, irrigation ratio was highest with $82.21 \%$ in Korkuteli irrigation scheme; total amount of irrigation water distributed in unit irrigated area was the lowest $\left(5532.32 \mathrm{~m}^{3} \mathrm{ha}^{-1}\right)$ in Mursal irrigation scheme; water supply rate was highest (3.74) in Alara irrigation scheme; benefit cost ratio was the lowest (0.76) in Manavgat irrigation scheme; output per unit irrigated area was highest $\left(1855.53 \$ \mathrm{ha}^{-1}\right)$ in Çıplaklı irrigation scheme and output per unit cubic meter irrigation water was the highest $\left(2.90 \$ \mathrm{~m}^{-3}\right)$ in Çıplaklı irrigation scheme. All performance indicators were aggregated in a single number (quality index) using factor analysis. According to the index, irrigation schemes were ranked. Korkuteli irrigation ranked the first (the most successful) with the highest score 1523.91 while Manavgat irrigation ranked the last with the lowest score -514.38 . Based on principle component analysis, agricultural efficiency indicators were the most effective factors on the success of the irrigation schemes. 


\section{Giriş}

Hızla artan dünya nüfusu ile birlikte yaşamsal ihtiyaçlar ve tüketimlerde artmaktadır. Yaşamsal açıdan ilk sırada gelen suyun kullanımı ve yönetimi bu açıdan son derece önemlidir. Son yıllarda küresel ısınmanın da etkisi ile su kaynakları azalmakta ve mevcut kaynakların verimli kullanımı ve yönetimi konusu ön plana çıkmaktadır.

Sulama sistemlerinin performans1, planlamada öngörülen hedeflerin gerçekleşme oranı olarak tanımlanmaktadır (Bulut ve Çakmak 2001). Ülkemizde sulama şebekelerinin başarısının artırılmasına yönelik 1993 yılından itibaren sulama şebekelerinin su kullanıcı örgütlerine devir programı uygulanmıştır. Svendsen ve Murray-Rust (2001), Türkiye'deki devir programlarının ulusal açıdan etkinliği üzerinde çalışmışlardır. Sulama şebekelerinin başarısını belirlemek için araştırmacılar farklı performans göstergeleri geliştirerek araştırmalar yapmışlardır (Rao 1993; Molden ve ark. 1998; Malano ve ark. 2004). Sulama performans1 üzerine ulusal ve uluslararası birçok çalışma yapılmıştır (Kuscu ve ark. 2009; Değirmenci ve Tanrıverdi 2016; Değirmenci ve ark. 2017; Arslan ve Değirmenci 2017; 2018). Abera ve ark. (2018) Etiyopya Tana Gölü bölgesinde Bebeks ve Shina sulama şebekelerinde düşük performansa neden olan teknik ve sosyopolitik nedenleri tespit etmek için yapılan araştırmada sulama şebekelerinin performansını belirlemede su temin oranı göstergesini kullanmışlardır. Bebeks sulama şebekesinde su temin oran1 0.58 iken, Shina sulama șebekesinde 0.73 ile 1.2 arasında değiştiği görülmüştür. Bareng ve ark. (2015), Filipinlerde Cagayan nehir havzasında dört sulama şebekesini performans göstergeleri ile değerlendirme yapmışlardır. Değerlendirme sonucunda su temin oranı 1.16-1.76 arasında, sulanan alan üretim değeri ise 37276.01 ile 71336.22 Peso ha $^{-1}$ arasında ve fayda masraf oranı ise 0.33-0.49 arasinda hesaplanmıştır.

$\mathrm{Bu}$ alanda ülkemizde farklı bölgelerde sulama şebekeleri performansları üzerine birçok çalışma yürütülmüştür. Çakmak (2001) Konya ovasında DSİ tarafindan inşa edilen ve sulama birliklerine devredilen, 7 sulama şebekesi üzerinde dört karşılaştırmalı gösterge kullanarak araştırma yapmıştır. Yapılan araştırmada proje alanı brüt üretim değeri $5391 \$$ ha $^{-1}$ ile en yüksek Atlantı sulamasında, $195 \$$ ha $^{-1}$ ile en düşük Ilgın sulamasında hesaplanmıştır. Akkuzu ve Mengü (2012) tarafından Aşağı Gediz Havzası Sulama birliklerinde yer alan 4 sulama şebekesi üzerinde yapılan araştırma neticesinde, sulanan alan birim üretim değerlerini $2136 \$$ ha $^{-1}$ ile $9066 \$$ ha $^{-1}$ arasında hesaplamışlardır. Kırnak ve Karaca (2017) Kayseri
Sarıoglan sulama birliğinde 2010-2015 yılı verileri ile yapmış oldukları araştırmada sulama oranı \%8.41-74.96, su temin oranı $\% 89-114$, sulama ücreti toplama oran1 \%50.43-85.00, proje alanı brüt üretim değeri 183.84-1702.44 $\$ \mathrm{ha}^{-1}$, fiilen sulanan alan brüt üretim değeri 1794.39-4868.77 $\$ \mathrm{ha}^{-1}$, saptırılan suya karşılık brüt üretim değeri $0.22-0.67 \$ \mathrm{~m}^{-3}$, sulama suyu ihtiyacına karşıllk brüt üretim değeri $0.20-0.57 \$ \mathrm{~m}^{-3}$ olarak hesaplanmıştır. Eliçabuk ve Topak (2017) Gevrekli Sulama Birliğinin su dağıtım ve üretim performansını 2008-2013 y1lları verilerini kullanarak değerlendirmişlerdir. Yapılan araştırmada birim sulama alanına dağıtılan toplam sulama suyu 665-1.301 $\mathrm{m}^{3} \mathrm{ha}^{-1}$, birim sulanan alana dağıtılan yıllık sulama suyu miktarı 2.577-5.273 $\mathrm{m}^{3} \mathrm{ha}^{-1}$, y1llik su temini oran1 0.51-1.04, sulanan alan brüt üretim değeri 6451.4-11501.8 $\mathrm{TL} \mathrm{ha}^{-1}$, şebekeye alınan birim sulama suyuna brüt üretim değeri $1.474-3.814 \mathrm{TL} \mathrm{ha}^{-1}$ olarak belirlenmiştir. Rodriguez-Diaz ve ark. (2008), İspanya'da sulama şebekelerini değerlendirmede Temel Bileşenler Analizi kullanmışlardır. $\mathrm{Bu}$ çalı̧̧manın amacı Antalya bölgesinde bulunan sulama şebekelerini performans göstergeleri ile değerlendirmektir. Bu doğrultuda toplam 13 sulama şebekesine ait 2006-2016 yılları arasındaki veriler kullanılarak 16 performans göstergesi hesaplanmıştır. Ayrıca faktör analizi kullanılarak çok sayıdaki performans göstergesi, tek sayıya indirgenerek sulama şebekelerinin başarı sıralaması yapılmıştır. Siralama sonucuna göre, sulama performansina en fazla etki eden göstergeler üzerinden şebekelerin zayıf ve güçlü yönleri ortaya konmuştur.

\section{Materyal ve Yöntem}

\subsection{Materyal}

Araştırmada Antalya bölgesinde bulunan sulama şebekeleri materyal olarak alınmıştır. Çalışmanın yapıldığı yıllarda, sulama şebekelerine ait 1. ürün olarak en fazla ekilen ürünler ve genel özellikleri Çizelge 1'de, sulama şebekelerinin konumları ise Şekil 1'de verilmiştir.

\subsection{Yöntem}

Çalışmada Molden ve ark. (1998), Rodriguez-Diaz ve ark. (2008), Zema ve ark. (2015) tarafından belirlenen karşılaştırma göstergeleri kullanılmıştır. Sulama alanı, sulanan alan, şebekeye alınan su miktarı, sulama suyu ihtiyacı, işletme, yönetim ve bakım giderleri, üretim değeri verileri DSİ'den temin edilmiştir. Yapılan çalışma kapsamında kullanılan göstergelerin hesaplama şekli Çizelge 2'de verilmiştir.

Çizelge 1. Sulama şebekelerinin genel özellikleri.

Table 1.General features of the irrigation schemes.

\begin{tabular}{|c|c|c|c|c|c|c|c|}
\hline \multirow{2}{*}{ Sulama Adı } & \multirow{2}{*}{$\begin{array}{c}\text { Sulama } \\
\text { Alanı (ha) }\end{array}$} & \multicolumn{2}{|c|}{ Sulama Şekli } & \multirow{2}{*}{$\begin{array}{c}\text { İşletmeye } \\
\text { Açıldığ1 Y11 }\end{array}$} & \multirow{2}{*}{\multicolumn{3}{|c|}{ Bitki Çeşidi }} \\
\hline & & Cazibe & Pompaj & & & & \\
\hline Alanya & 1100 & $\mathrm{X}$ & $\mathrm{x}$ & 1948 & Narenciye (\%57) & Muz (\%36) & Sebze (\%3) \\
\hline Manavgat & 6300 & $\mathrm{x}$ & $\mathrm{x}$ & 1958 & Bostan (\%22) & Narenciye (\%20) & Yerfistığ \\
\hline Aksu & 18700 & $\mathrm{x}$ & $\mathrm{x}$ & 1962 & Sebze $(\% 22)$ & Pamuk (\%19) & Narenciye (\%12) \\
\hline Kırkgözler Yeniköy & 1000 & $\mathrm{x}$ & - & 1962 & Meyve (\%39) & Çiçek $(\% 24)$ & Yem Bitkileri (\%16) \\
\hline Köprüçay & 16673 & $\mathrm{x}$ & $\mathrm{x}$ & 1968 & Narenciye (\%25) & Misir $(\% 20)$ & Pamuk (\%16) \\
\hline Alara & 2000 & $\mathrm{x}$ & $\mathrm{x}$ & 1968 & Narenciye (\%25) & Bostan (\%24) & $\operatorname{Muz}(\% 11)$ \\
\hline Korkuteli & 4000 & $\mathrm{x}$ & - & 1974 & Meyve (\%100) & - & - \\
\hline Boğaçay & 1420 & $\mathrm{x}$ & - & 1977 & Narenciye (\%79) & Sebze $(\% 12)$ & Meyve (\%17) \\
\hline Gazipaşa & 1400 & $\mathrm{x}$ & - & 1985 & Sebze $(\% 63)$ & Çilek (\%16) & Narenciye (\%8) \\
\hline Mursal & 1000 & - & $\mathrm{x}$ & 1986 & Meyve (\%40) & Hububat (\%29) & Şeker Pancarı (\%27) \\
\hline Çıplaklı & 1000 & - & $\mathrm{x}$ & 1997 & Meyve (\%51) & Zeytinlik(\%41) & Sebze $(\% 7)$ \\
\hline Çayboğazı & 11350 & $\mathrm{x}$ & - & 2005 & Meyve (\%88) & Ş. Pancarı(\%7) & Sebze $(\% 5)$ \\
\hline Köprüçay Deniztepesi & 3250 & - & $\mathrm{x}$ & 2005 & Sebze $(\% 35)$ & Meyve (\%18) & Fidan (\%13) \\
\hline
\end{tabular}




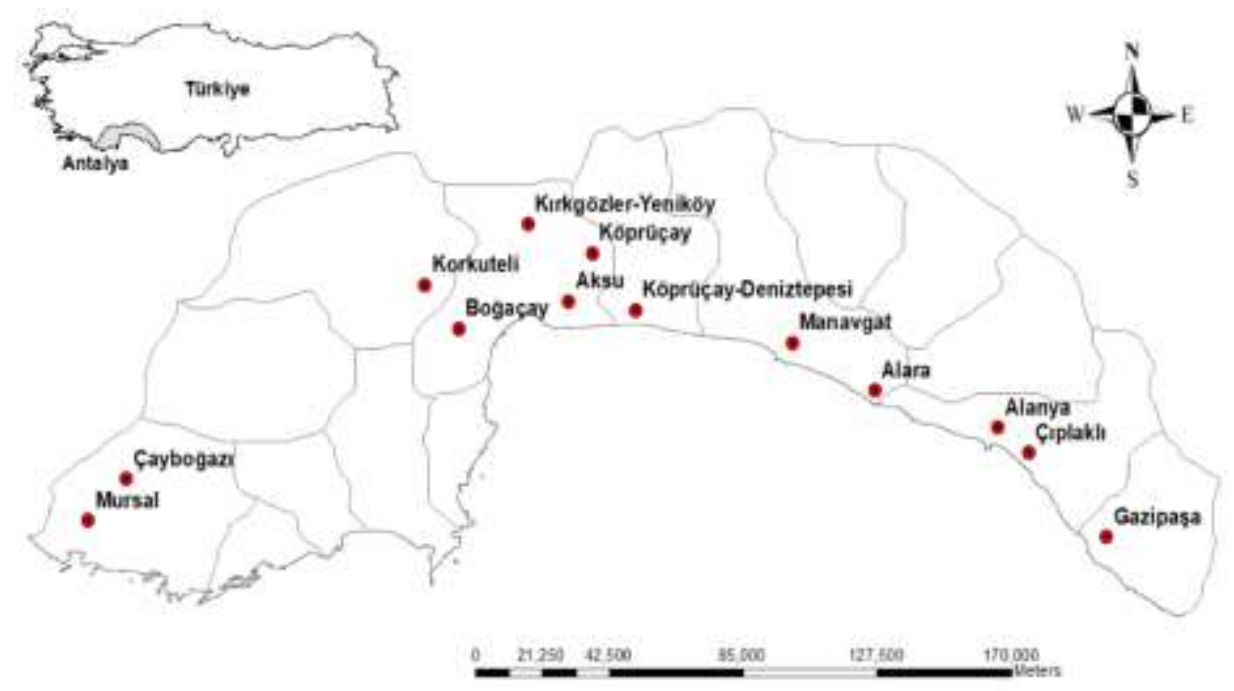

Şekil 1. Sulama şebekelerinin konumları.

Figure 1. Locations of the irrigation schemes.

Çizelge 2. Performans göstergelerinin hesaplanması.

Table 2. Calculation of the performance indicators.

\begin{tabular}{|c|c|c|c|c|}
\hline $\begin{array}{c}\text { Gösterge } \\
\text { Grubu }\end{array}$ & Göstergeler & Tanım & $\begin{array}{c}\text { Gösterge } \\
\text { kodu }\end{array}$ & $\begin{array}{c}\text { Etki } \\
\text { faktörü̈ }\end{array}$ \\
\hline \multirow{8}{*}{ 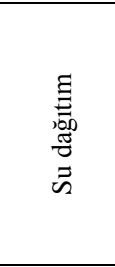 } & Sulama oran $(0 \%)$ & Sulanan alan $* 100$ & \multirow{2}{*}{ A } & \multirow{2}{*}{+1} \\
\hline & Sulama oranı (\%) & Sulama alanı & & \\
\hline & Birim sulanan alana dağıtılan yıllık sulama suyu & Şebekeye alınan toplam su miktarı & \multirow{2}{*}{ B } & \multirow{2}{*}{-1} \\
\hline & miktarı $\left(\mathrm{m}^{3} \mathrm{ha}^{-1}\right)$ & Sulanan alan & & \\
\hline & Birim sulama alanına dağıtılan yıllık sulama suyu & Şebekeye alınan toplam su miktarı & \multirow{2}{*}{$\mathrm{C}$} & \multirow{2}{*}{-1} \\
\hline & miktarı $\left(\mathrm{m}^{3} \mathrm{ha}^{-1}\right)$ & Sulama alanı & & \\
\hline & \multirow{2}{*}{ Su temin oranı } & Şebekeye alınan toplam su miktarı & \multirow{2}{*}{$\mathrm{D}$} & \multirow{2}{*}{-1} \\
\hline & & Toplam sulama suyu ihtiyacı & & \\
\hline \multirow{14}{*}{ 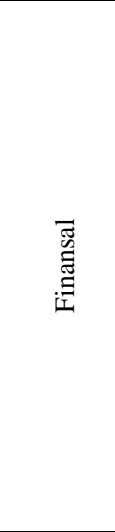 } & \multirow{2}{*}{$\begin{array}{l}\text { Birim sulanan alana harcanan işletme-bakım } \\
\text { masrafları }\left(\$ \mathrm{ha}^{-1}\right)\end{array}$} & Toplam işletme ve bakım masrafları & \multirow{2}{*}{$\mathrm{E}$} & \multirow{2}{*}{-1} \\
\hline & & Sulanan alanı & & \\
\hline & Birim sulama alanına harcanan işletme-bakım & Toplam işletme ve bakım masrafları & \multirow[t]{2}{*}{$\mathrm{F}$} & \multirow[t]{2}{*}{-1} \\
\hline & \multirow{3}{*}{$\begin{array}{c}\text { Birim sulama suyu miktarına karşılık harcanan } \\
\text { işletme-bakım masrafları }\left(\$ \mathrm{~m}^{-3}\right)\end{array}$} & Sulama alanı & & \\
\hline & & Toplam işletme ve bakım masrafları & \multirow{2}{*}{ G } & \multirow{2}{*}{-1} \\
\hline & & Şebekeye alınan toplam su miktarı & & \\
\hline & İsletme-bakım toplam gider oranı & Toplam işletme ve bakım masrafları & \multirow{2}{*}{$\mathrm{H}$} & \multirow{2}{*}{+1} \\
\hline & 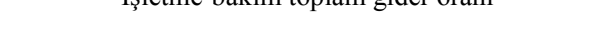 & Toplam gider & & \\
\hline & \multirow{2}{*}{ Birim sulanan alana harcanan toplam gider $\left(\$ \mathrm{ha}^{-1}\right)$} & Toplam gider & \multirow{2}{*}{ I } & \multirow{2}{*}{-1} \\
\hline & & $\begin{array}{l}\text { Sulanan alan } \\
\text { Toplam gider }\end{array}$ & & \\
\hline & Birim sulama alanına harcanan toplam gider $\left(\$ \mathrm{ha}^{-1}\right)$ & & $\mathrm{J}$ & -1 \\
\hline & \multirow{2}{*}{ Birim sulama suyuna karşılık toplam gider $\left(\$ \mathrm{~m}^{-3}\right)$} & Toplam gider & \multirow{2}{*}{$\mathrm{K}$} & \multirow{2}{*}{-1} \\
\hline & & $\overline{\text { Şebekeye alınan toplam su miktarı }}$ & & \\
\hline & Fayda masraf oran 1 & DSI İzleme ve değerlendirme raporlarından alınmıştır & $\mathrm{L}$ & +1 \\
\hline \multirow{8}{*}{ 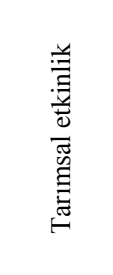 } & Birim sulanan alan üretim değeri $\left(\$\right.$ ha $\left.^{-1}\right)$ & Üretim değeri & $\mathrm{M}$ & +1 \\
\hline & & $\overline{\text { Sulanan alan }}$ & & \\
\hline & Birim sulama alanı üretim değeri $\left(\$\right.$ ha $\left.^{-1}\right)$ & Uretim değeri & $\mathrm{N}$ & +1 \\
\hline & & Sulama alanı & & \\
\hline & Bırım şebekeye alınan sulama suyu üretım değerı & Uretim degerı & $\mathrm{O}$ & +1 \\
\hline & $(\$ \mathrm{~m}$ & Şebekeye alınan toplam su miktarı & & \\
\hline & Birim sulama suyu ihtiyacına karşılık üretim değeri & Üretim değeri & $P$ & +1 \\
\hline & $\left(\$ \mathrm{~m}^{-3}\right)$ & $\overline{\text { Toplam sulama suyu ihtiyacl }}$ & 1 & T1 \\
\hline
\end{tabular}

"Etki faktörü: Sulama şebekesine pozitif veya negatif etkiyi ifade etmektedir (Bkz. Kalite İndeksi).

Üretim değeri göstergeleri hesaplanırken T.C Merkez bankasına ait 2006-2016 y1llarına ait ortalama dolar kuru baz alınmıştır. Çalışma yapılan sulama şebekelerine ait tamamlayıcı istatistiksel veriler Microsoft Excel programında hesaplanmıştır. Sulama şebekelerinin performans göstergeleri arasındaki ilişkiler Pearson Korelasyon ile incelenmiştir (Özdamar 2015). Analizler istatistik paket programı yardımı ile yapılmıştır. Fazla sayıdaki verileri indirgemek amacı ile Temel Bileşenler Analizi yapılmıştır. Benzer özelliklere sahip olan sulama şebekelerini kendi aralarında gruplandırma ve değerlendirme amacıyla kümeleme analizi yapılmıştır. Kümeleme analizi sulama şebekesine en fazla etki eden temel bileşenler analizi sonucunda elde edilen bileşen 1'e göre yapılmıştır. Temel bileşen analizde elde edilen bileşen yükleri kullanılarak sulama şebekeleri için 
kalite indeksi hesaplaması yapılmıştır (Rodriguez-Diaz ve ark. 2008; Córcoles ve ark. 2010; Zema ve ark. 2015).

Kalite indeksi hesaplamasında aşağıdaki işlem sırasıyla uygulanmıştır.

1) Göstergelerin standardizasyonu (orijinal veri matrisinin sıfir ve bir arasında değerlere dönüştürülmesi),

2) Korelasyon analizi (göstergeler arasındaki ilişkiyi incelemek),

3) Temel bileşenler analizinin varimax yöntemi kullanılarak yapılması (bu yöntem araştırmacılar tarafindan en yaygın ve geçerli yöntemdir) ve oluşan bileşenlerin değişkenleri açıklama yüzdesinin hesaplanması,

4) Çalışmada kullanılacak temel bileşen sayısının seçilmesi (değişkenleri açıklama yüzdesi $\% 70$ ve üstü seçilmiştir),

5) Kalite indeksinin etki faktörüne (etki faktörü +1 olan göstergelerin maksimum, -1 olanların minimum olması beklenir) göre hesaplanması (Alpar 2017).

Sulama şebekelerinin değerlendirilmesinde kullanılan gösterge verilerinin temel bileşenler analizi için uygunluğunun değerlendirilmesinde Kaiser-Meyer-Olkin (KMO) ve Barlett testi uygulanmıştır. Ki-kare istatistiği olan Bartlett testi sonucu ne kadar yüksek ise anlamlı olma olasılığı o kadar yüksektir (Alpar 2017).

\section{Bulgular ve Tartışma}

Sulama şebekelerine ait performans göstergelerinin temel bileşenler analizine uygunluğu için Kaiser-Meyer-Olkin (KMO) ve Barlett uygunluk testi yapılmış ve sonuçlar Çizelge 3'te verilmiştir. Yapılan analiz neticesinde KMO değeri $0.596>0.5$ ve önemlilik seviyesi $0.000<0.01$ olarak hesaplanmıştır. Bu sonuç verilerin temel bileşeneler analizinde hesaplanmasının uygun olduğunu göstermektedir.

Çizelge 3. Temel bileşenler analizi için verilerinin uygunluğunun değerlendirilmesi.

Table 3. Confirmity test to data for principal component analysis

\begin{tabular}{|c|c|c|}
\hline \multicolumn{3}{|c|}{ KMO ve Bartlett Testi } \\
\hline Kaiser-Mey & \multicolumn{2}{|c|}{ Değerlerinin Yeterliliği } \\
\hline \multirow{3}{*}{ Bartlett Testi } & Ki-Kare & 2994.266 \\
\hline & $\mathrm{Sd}$ & 120 \\
\hline & $\mathrm{P}$ & 0.000 \\
\hline
\end{tabular}

Yapılan çalışmada sulama şebekelerinin 2006-2016 yıllarına ait hesaplanan performans göstergelerinin ortalama ve standart sapma değerleri Çizelge 4'te verilmiştir. Sulama oranı en yüksek \%82.21 ile Korkuteli sulama şebekesinde gerçekleşirken $\% 20.48$ ile en düşük Gazipaşa sulama şebekesinde gerçekleşmiştir. Birim sulama alanına dağıtılan toplam sulama suyu miktarı $10759.43 \mathrm{~m}^{3} \mathrm{ha}^{-1}$ ile en yüksek Boğaçay sulamasında en düşük $2239.16 \mathrm{~m}^{3} \mathrm{ha}^{-1}$ ile Köprüçay Deniztepesi sulamasında hesaplanmıştır. Fayda masraf oranı en düşük 0.76 ile Manavgat sulama şebekesinde iken en yüksek 15.69 ile Mursal sulamasında olmuştur. Birim sulama alanı üretim değeri $14486.26 \$$ ha $^{-1}$ ile en yüksek Korkuteli sulama şebekesinde, $1395.46 \$$ ha $^{-1}$ ile en düşük Manavgat sulama şebekesinde hesaplanmıştır.

Pearson korelasyon sonuçları Çizelge 5'te verilmiştir. Analiz sonucunda E: Birim sulanan alana harcanan işletme- bakım masrafları ile F: Birim sulama alanına harcanan işletmebakım masrafları arasında $(r=0.784)$, ve G: Birim sulama suyu miktarına karşılık harcanan işletme-bakım masrafları arasında $(\mathrm{r}=0.719)$ yüksek korelasyon hesaplanmıştır. I: Birim sulanan alana harcanan toplam gider ile J: Birim sulama alanına harcanan toplam gider arasında $(\mathrm{r}=-0.796)$ yüksek korelasyon olduğu görülmüştür. I: Birim sulanan alana harcanan toplam gider ile K: Birim sulama suyuna karşılık toplam gider arasında $(\mathrm{r}=0.754)$, A: Sulama oranı ile N: Birim sulama alanı üretim değeri arasında $(\mathrm{r}=0.773), \mathrm{M}$ : Birim sulanan alan üretim değeri ile N: Birim sulama alanı üretim değeri arasında $(r=0.857)$ yüksek korelasyon bulunmuştur.

Sulama şebekelerine ait performans göstergelerinin gruplanarak başarı sıralamalarını belirlemek için yapılan temel bileşenler analizi sonuçları Çizelge 6'da verilmiştir. Yapılan analiz sonucunda göstergelerin açıklama düzeyi bileşen 1 'de $\% 31.41$, bileşen 2'de \%23.54 ve bileşen 3'te ise \%17.07 olmak üzere toplam açılama düzeyi $\% 72.03$ olarak geçekleşmiştir. Bileşen 1'de yükleri 0.921, 0.899, 0.760, 0.693 olan P, M, N ve $\mathrm{O}$ göstergeleri aralarında pozitif korelasyon vardır. Bileşen 2'de $C$ ve A göstergeleri arasında pozitif, $K$ göstergesi ile aralarında negatif korelasyon vardır. Bileșen 3'te F, E, H ve G göstergeleri arasında pozitif korelasyon bulunmaktadır.

Sulama şebekelerine ait çok sayıdaki veri faktör analizi ile indirgenerek kalite indeksi ve başarı sıralaması hesaplanmıştır. Kalite indekslerine göre yapılan başarı sıralaması Çizelge 7'de verilmiştir. Yapılan başarı sıralamasında sırayla Korkuteli, Çıplaklı ve Mursal sulamaları üst sıralarda yer almıştır. Sulama şebekeleri verilerine baktığımızda ortalama sulama oranlarının, birim şebekeye alınan sulama suyu üretim değerleri ve birim sulama suyu ihtiyacına karşılık üretim değerleri ortalamalarının yüksek olduğu görülmüştür. Alanya, Alara ve Manavgat sulamaları alt sıralarda yer almıştır. Bu sulama şebekelerinin birim sulama alanına harcanan işletme-bakım masraflarının ve birim sulama alanına harcanan toplam gider değerlerinin yüksek olduğu belirlenmiştir.

Rodriguez-Diaz ve ark. (2008) İspanya Endülüs Bölgesinde 9 sulama şebekesinde yaptıkları çalışmada Faktör analizinden elde edilen skorları kalite indeksi olarak adlandırmışlardır. Yapılan çalışmada değerlendirdikleri sulama şebekelerini 4 gruba ayırmışlardır. Bu gruplar incelendiğinde, birim alandan ve birim sulama suyu miktarından elde edilen üretim değeri en yüksek sulama şebekelerinin grup içerisinde bulunduğu görünmektedir. İkinci grup incelendiğinde çalışan sayısının yüksek olmas1, yüksek miktarda su tüketimi ve düşük üretim değeri olan sulama şebekelerinin yer aldığı anlaşılmaktadır. Üçüncü grup incelendiğinde düşük düzeyle işletme yönetim ve bakım masrafları dikkat çekmektedir. Dördüncü ve son grup ise yüksek enerji giderleri ve yüksek üretim değeri olduğu görülmektedir. Dokuz adet sulama şebekesinin kalite indeksi sıralamasına göre tüm performans göstergeleri dikkate alındığında Piedras-Guadiana sulama şebekesi birinci sırada, en başarılı sulama şebekesi olduğu görülmektedir. $\mathrm{Bu}$ sulama şebekesinin birinci sırada yani en başarılı olmasının sebebi birim sulama suyu üretim değerinin yüksek olması, birim alandan elde edilen üretim değerinin yüksek olması ve sulama suyunu tasarruflu kullandığ 1 görülmektedir. Benzer diğer bir çalışmayı Kartal ve ark. (2019) üç sulama şebekesini değerlendirmek amacıyla yapmışlardır. Boğaçay sulama şebekesinin yüksek performans göstermesi, üretim değeri göstergelerinde yüksek olması ile açıklanmıştır. Yapılan bu güncel çalışmada ise Antalya bölgesinde Korkuteli sulama şebekesi yüksek performans göstermiştir. Korkuteli sulama 
Çizelge 4. Sulama şebekelerine ait betimsel istatistikler.

Table 4. Descriptive statistics of performance indicators.

\begin{tabular}{|c|c|c|c|c|c|c|c|c|c|c|c|c|c|c|c|c|}
\hline Sulama şebekeleri & $\mathrm{A}$ & $\mathrm{B}$ & $\mathrm{C}$ & $\mathrm{D}$ & $\mathrm{E}$ & $\mathrm{F}$ & G & $\mathrm{H}$ & I & $\mathrm{J}$ & $\mathrm{K}$ & $\mathrm{L}$ & $\mathrm{M}$ & $\mathrm{N}$ & $\mathrm{O}$ & $P$ \\
\hline \multirow{2}{*}{ Alanya } & 51.38 & 17586.38 & 8098.10 & 2.27 & 732.26 & 315.19 & 0.044 & 38.34 & 1922.99 & 817.87 & 0.115 & 4.74 & 11915.66 & 6680.88 & 0.83 & 1.69 \\
\hline & (19.47) & (7072.68) & $(3586.60)$ & $(0.88)$ & $(324.35)$ & (59.15) & $(0.016)$ & (2.44) & (896.28) & (118.69) & $(0.038)$ & (1.89) & $(5136.67)$ & $(4157.83)$ & $(0.52)$ & $(0.88)$ \\
\hline \multirow{2}{*}{ Manavgat } & 29.45 & 13548.24 & 3981.10 & 2.82 & 406.81 & 119.53 & 0.031 & 9.75 & 4152.29 & 1212.69 & 0.310 & 0.76 & 4703.92 & 1395.46 & 0.36 & 0.94 \\
\hline & (2.32) & (1791.43) & (548.74) & $(0.73)$ & $(117.72)$ & (35.99) & $(0.010)$ & $(2.23)$ & (715.75) & $(163.26)$ & $(0.059)$ & $(0.32)$ & (1131.53) & (391.16) & $(0.11)$ & $(0.20)$ \\
\hline \multirow{2}{*}{ Aksu } & 59.95 & 15825.38 & 9382.73 & 2.54 & 118.95 & 71.43 & 0.008 & 18.85 & 1170.70 & 696.78 & 0.082 & 4.11 & 7965.25 & 4836.84 & 0.56 & 1.31 \\
\hline & $(4.86)$ & $(4087.82)$ & $(2275.12)$ & $(0.67)$ & (31.23) & (18.74) & $(0.003)$ & $(30.32)$ & (385.73) & (222.63) & $(0.036)$ & $(1.32)$ & $(2376.56)$ & $(1624.90)$ & $(0.26)$ & $(0.49)$ \\
\hline \multirow{2}{*}{ Kırkgözler Yeniköy } & 54.67 & 13292.09 & 6813.64 & 1.89 & 178.96 & 92.06 & 0.013 & 32.02 & 559.27 & 289.76 & 0.043 & 13.66 & 15513.00 & 8438.24 & 1.29 & 2.27 \\
\hline & $(10.48)$ & (4891.48) & (1096.09) & $(0.81)$ & $(79.80)$ & (27.74) & (0.003) & (7.11) & (213.11) & (67.69) & $(0.008)$ & (5.69) & (4699.18) & $(3060.66)$ & $(0.58)$ & $(0.86)$ \\
\hline \multirow{2}{*}{ Köprüçay } & 62.56 & 14437.77 & 8817.53 & 2.36 & 147.39 & 92.25 & 0.011 & 20.29 & 730.91 & 451.11 & 0.052 & 5.35 & 5919.06 & 3779.54 & 0.46 & 0.86 \\
\hline & (6.11) & (3738.83) & (1492.52) & (1.05) & (49.42) & $(33.90)$ & $(0.005)$ & (7.03) & (148.71) & $(68.80)$ & $(0.010)$ & (2.98) & (1889.41) & (1473.28) & $(0.24)$ & $(0.17)$ \\
\hline \multirow{2}{*}{ Alara } & 37.80 & 13729.91 & 5060.41 & 3.74 & 608.73 & 216.95 & 0.044 & 23.45 & 2520.79 & 916.95 & 0.183 & 2.07 & 8308.32 & 3198.91 & 0.64 & 2.35 \\
\hline & (6.35) & $(2444.91)$ & (445.02) & $(0.98)$ & (223.29) & (51.69) & $(0.012)$ & (4.04) & (628.83) & (110.13) & $(0.029)$ & $(0.56)$ & $(2485.12)$ & (1357.46) & $(0.27)$ & (1.16) \\
\hline \multirow{2}{*}{ Korkuteli } & 82.21 & 6679.72 & 5451.86 & 1.22 & 197.19 & 158.95 & 0.029 & 17.20 & 1072.75 & 874.86 & 0.163 & 8.01 & 18271.70 & 14846.26 & 2.75 & 3.33 \\
\hline & $(5.56)$ & (1192.03) & $(821.46)$ & $(0.33)$ & (123.31) & (92.04) & $(0.013)$ & $(6.31)$ & (239.96) & (167.30) & $(0.028)$ & (2.33) & $(6268.81)$ & $(4644.39)$ & $(0.78)$ & (1.42) \\
\hline \multirow{2}{*}{ Boğaçay } & 76.99 & 14024.18 & 10759.43 & 2.04 & 319.98 & 223.98 & 0.021 & 47.56 & 585.99 & 444.31 & 0.042 & 9.51 & 14061.40 & 10846.42 & 1.01 & 2.07 \\
\hline & $(6.78)$ & (1464.47) & $(1152.22)$ & $(0.52)$ & (441.64) & (273.58) & $(0.027)$ & $(55.22)$ & (136.99) & (80.10) & (0.009) & (4.72) & $(3688.31)$ & $(3241.76)$ & $(0.28)$ & $(0.77)$ \\
\hline \multirow{2}{*}{ Gazipaşa } & 20.48 & 6821.81 & 1366.88 & 2.58 & 554.73 & 111.95 & 0.086 & 16.61 & 3343.18 & 680.32 & 0.541 & 1.44 & 10969.30 & 2217.17 & 1.77 & 4.14 \\
\hline & $(2.00)$ & $(2387.12)$ & (409.63) & $(1.20)$ & (126.90) & (19.66) & $(0.016)$ & (2.92) & (484.16) & (85.74) & $(0.158)$ & $(0.52)$ & (2993.06) & $(548.31)$ & (0.69) & (1.54) \\
\hline \multirow{2}{*}{ Mursal } & 61.00 & 5532.32 & 3273.67 & 0.94 & 205.97 & 120.10 & 0.042 & 36.25 & 559.63 & 327.83 & 0.120 & 15.69 & 12092.57 & 7367.20 & 2.76 & 2.16 \\
\hline & $(10.20)$ & $(2136.13)$ & (1099.93) & $(0.369)$ & (79.01) & (30.44) & $(0.020)$ & (3.51) & (169.76) & $(57.80)$ & $(0.067)$ & (4.61) & $(2269.36)$ & (1898.19) & (1.67) & $(0.62)$ \\
\hline \multirow{2}{*}{ Çıplaklı } & 64.02 & 7305.32 & 4633.55 & 1.16 & 147.23 & 87.65 & 0.023 & 10.63 & 1411.03 & 817.76 & 0.216 & 9.38 & 18553.53 & 12581.70 & 2.90 & 3.08 \\
\hline & (20.89) & $(2587.23)$ & (2146.83) & $(0.39)$ & $(40.31)$ & (19.80) & $(0.010)$ & (1.47) & $(455.02)$ & (107.05) & $(0.090)$ & (4.41) & (4401.41) & (6304.18) & (1.33) & (1.16) \\
\hline \multirow{2}{*}{ Çayboğazı } & 37.93 & 8635.55 & 2976.55 & 1.07 & 76.42 & 29.31 & 0.011 & 3.10 & 4176.12 & 1361.27 & 0.449 & 4.18 & 16202.95 & 6218.92 & 2.28 & 2.01 \\
\hline & (11.79) & $(3470.76)$ & (1006.47) & $(0.50)$ & (18.83) & (12.12) & $(0.006)$ & (2.48) & (2684.24) & (720.45) & $(0.134)$ & (3.21) & (3981.13) & $(2704.38)$ & (1.15) & $(0.75)$ \\
\hline \multirow{2}{*}{ Köprüçay Deniztepesi } & 28.15 & 8446.43 & 2239.16 & 1.61 & 385.32 & 108.45 & 0.062 & 20.62 & 1921.85 & 556.38 & 0.279 & 3.93 & 8019.81 & 2236.66 & 1.02 & 1.48 \\
\hline & (6.14) & (3295.99) & (521.99) & $(1.02)$ & (460.44) & (129.19) & $(0.100)$ & (12.74) & (964.67) & (292.62) & $(0.213)$ & (5.14) & $(2150.32)$ & (780.29) & $(0.35)$ & $(0.67)$ \\
\hline
\end{tabular}


Çizelge 5. Performans göstergeleri arasindaki Pearson korelasyon katsayıları.

Table 5. Pearson correlation coefficient between performance indicators.

\begin{tabular}{|c|c|c|c|c|c|c|c|c|c|c|c|c|c|c|c|c|}
\hline $\begin{array}{l}\text { Performans } \\
\text { göstergeleri }\end{array}$ & A & B & $\mathrm{C}$ & D & E & F & G & $\mathrm{H}$ & I & $\mathrm{J}$ & $\mathrm{K}$ & $\mathrm{L}$ & M & $\mathrm{N}$ & $\mathrm{O}$ & $\mathrm{P}$ \\
\hline $\mathrm{A}$ & 1 & -.135 & $.570^{* *}$ & $-.353^{* *}$ & $-.421^{* *}$ & .067 & $-.326^{* *}$ & .152 & $-.684^{* *}$ & $-.241^{* *}$ & $-.590^{* *}$ & $.582^{* *}$ & $.411^{* *}$ & $.773^{* *}$ & $.316^{* *}$ & .080 \\
\hline B & & 1 & $.664^{* *}$ & $.661^{* *}$ & $.264^{* *}$ & $.198^{*}$ & $-.273^{* *}$ & $.204^{*}$ & .082 & .027 & $-.416^{* *}$ & $-.271^{* *}$ & $-.294^{* *}$ & $-.265^{* *}$ & $-.693^{* *}$ & $-.357^{* *}$ \\
\hline $\mathrm{C}$ & & & 1 & $.277^{* *}$ & -.133 & $.192^{*}$ & $-.404^{* *}$ & $.281^{* *}$ & $-.436^{* *}$ & $-.190^{*}$ & $-.686^{* *}$ & .145 & .018 & $.279^{* * *}$ & $-.392^{* *}$ & $-.228^{* * *}$ \\
\hline D & & & & 1 & $.330^{* *}$ & .158 & -.044 & .041 & $.235^{* *}$ & .102 & -.134 & $-.420^{* *}$ & $-.345^{* *}$ & $-.385^{* *}$ & $-.574^{* *}$ & .073 \\
\hline E & & & & & 1 & $.784^{* *}$ & $.719^{* *}$ & $.472^{* *}$ & $.330^{* *}$ & .154 & $.247^{* *}$ & $-.349^{* * *}$ & $-.185^{*}$ & $-.282^{* *}$ & $-.232^{* *}$ & .045 \\
\hline $\mathrm{F}$ & & & & & & 1 & $.500^{* *}$ & $.744^{* *}$ & -.018 & .070 & -.077 & -.086 & .062 & .108 & -.098 & .071 \\
\hline G & & & & & & & 1 & $.235^{* *}$ & $.255^{* *}$ & .095 & $.565^{* *}$ & $-.200^{*}$ & -.081 & $-.182^{*}$ & .150 & $.193^{*}$ \\
\hline $\mathrm{H}$ & & & & & & & & 1 & $-.313^{* *}$ & $-.350^{* *}$ & $-.321^{* *}$ & $.209^{*}$ & .040 & .087 & -.090 & -.017 \\
\hline I & & & & & & & & & 1 & $.796^{* *}$ & $.754^{* *}$ & $-.606^{* *}$ & $-.207^{*}$ & $-.450^{* *}$ & $-.190^{*}$ & -.009 \\
\hline $\mathrm{J}$ & & & & & & & & & & 1 & $.554^{* *}$ & $-.489^{* *}$ & .011 & -.067 & -.031 & .018 \\
\hline K & & & & & & & & & & & 1 & $-.461^{* *}$ & -.037 & $-.307^{* *}$ & $.239^{* *}$ & $.222^{* *}$ \\
\hline L & & & & & & & & & & & & 1 & $.571^{* *}$ & $.663^{* *}$ & $.498^{* *}$ & $.270^{* *}$ \\
\hline M & & & & & & & & & & & & & 1 & $.857^{* *}$ & $.686^{* *}$ & $.708^{* *}$ \\
\hline $\mathrm{N}$ & & & & & & & & & & & & & & 1 & $.616^{* *}$ & $.514^{* *}$ \\
\hline $\mathrm{O}$ & & & & & & & & & & & & & & & 1 & $.576^{* *}$ \\
\hline $\mathrm{P}$ & & & & & & & & & & & & & & & & 1 \\
\hline
\end{tabular}

A: Sulama oranı (\%), B: Birim sulanan alana dağıtılan toplam sulama suyu miktarı $\left(\mathrm{m}^{3} \mathrm{ha}^{-1}\right)$, C: Birim sulama alanına dağtılan toplam sulama suyu miktarı $\left(\mathrm{m}^{3}\right.$ ha $\left.{ }^{-1}\right)$, D: Su temin oranı, E: Birim sulanan alana harcanan işletme-bakım masrafları $\left(\$\right.$ ha $\left.^{-1}\right)$, F: Birim sulama alanına harcanan isletme-bakım masrafları $\left(\$ \mathrm{ha}^{-1}\right)$, G: Birim sulama suyu miktarına karsıllik harcanan isletme-bakım masrafları $\left(\$ \mathrm{~m}^{-3}\right)$, H: İsletme-bakım toplam gider oranı, I: Birim sulanan alan harcanan toplam gider $\left(\$ \mathrm{ha}^{-1}\right)$, J: Birim sulama alanına harcanan toplam gider $\left(\$ \mathrm{ha}^{-1}\right)$, K: Birim sulama suyuna karşıllk toplam gider $\left(\$ \mathrm{~m}^{-3}\right)$, L: Fayda masraf oranı $\mathrm{M}$ : Birim sulanan alan üretim değeri $\left(\$\right.$ ha $\left.{ }^{-1}\right)$, N: Birim sulama alanı üretim değeri $\left(\$ h^{-1}\right)$, O: Birim şebekeye alınan sulama suyu üretim değeri P: Birim sulama suyu ihtiyacına karşıllik üretim değeri $\left(\$ \mathrm{~m}^{-3}\right)$. 
Çizelge 6. Temel bileşenler analizi sonucunda elde edilen bileşen yükleri.

Table 6. Principal component matrix.

\begin{tabular}{cccc}
\hline \multirow{2}{*}{ Göstergeler } & \multicolumn{3}{c}{ Bileşenler } \\
\cline { 2 - 4 } & \multicolumn{3}{c}{2} \\
\hline $\mathrm{P}$ & .921 & -.269 & .051 \\
$\mathrm{M}$ & .899 & .212 & -.006 \\
$\mathrm{~N}$ & .760 & .533 & .006 \\
$\mathrm{O}$ & .693 & -.143 & -.066 \\
$\mathrm{C}$ & -.081 & .841 & .069 \\
$\mathrm{~A}$ & .298 & .776 & -.043 \\
$\mathrm{~K}$ & .062 & -.687 & .053 \\
$\mathrm{~F}$ & .060 & .176 & .947 \\
$\mathrm{E}$ & -.084 & -.285 & .859 \\
$\mathrm{H}$ & -.019 & .215 & .775 \\
$\mathrm{G}$ & .030 & -.530 & .683 \\
$\mathrm{~J}$ & .039 & .006 & -.011 \\
$\mathrm{I}$ & -.118 & -.426 & .011 \\
$\mathrm{~L}$ & .480 & .300 & -.080 \\
$\mathrm{D}$ & -.069 & -.084 & .082 \\
$\mathrm{~B}$ & -.313 & .402 & .129 \\
\hline Açılama düzeyi & 31.41 & 23.54 & 17.07 \\
(\%) & & &
\end{tabular}

Toplam açıklama $\quad 72.03$

düzeyi $(\%)$

A: Sulama oranı (\%), B: Birim sulanan alana dağıtılan toplam sulama suyu miktarı $\left(\mathrm{m}^{3} \mathrm{ha}^{-1}\right), \mathrm{C}$ : Birim sulama alanına dağıtılan toplam sulama suyu miktarı $\left(\mathrm{m}^{3} \mathrm{ha}^{-1}\right)$, D: Su temin oranı, E: Birim sulanan alana harcanan işletme-bakım masrafları (\$ $\left.\mathrm{ha}^{-1}\right)$, F: Birim sulama alanına harcanan işletme-bakım masrafları $\left(\$ \mathrm{ha}^{-1}\right)$, G: Birim sulama suyu miktarına karşılık harcanan işletme-bakım masrafları $\left(\$ \mathrm{~m}^{-3}\right)$, H: İşletme-bakım toplam gider oranı, I: Birim sulanan alana harcanan toplam gider $\left(\$ \mathrm{ha}^{-1}\right)$, J: Birim sulama alanına harcanan toplam gider $\left(\$ \mathrm{ha}^{-1}\right), \mathrm{K}$ : Birim sulama suyuna karşılık toplam gider $\left(\$ \mathrm{~m}^{-3}\right)$, L: Fayda masraf oranı.

Çizelge 7. Sulama şebekelerinin başarı sıralaması.

Table 7. Ranking of success of the irrigation schemes.

\begin{tabular}{lcc}
\hline \multicolumn{1}{c}{ Sulama Şebekesi } & Kalite indeksi & Sıralama \\
\hline Korkuteli & 1523.91 & 1 \\
Çılaklı & 1394.36 & 2 \\
Mursal & 1049.55 & 3 \\
Kırkgözler Yeniköy & 860.30 & 4 \\
Boğaçay & 645.32 & 5 \\
Çayboğazı & 631.50 & 6 \\
Gazipaşa & 166.07 & 7 \\
Aksu & 101.85 & 8 \\
Köprüçay & 505.23 & 9 \\
Köprüçay Deniztepesi & -34.82 & 10 \\
Alanya & -140.01 & 11 \\
Alara & -181.92 & 12 \\
Manavgat & -514.38 & 13 \\
\hline
\end{tabular}

şebekesinin birim sulanan alan üretim değeri, birim sulama alanı üretim değeri, birim şebekeye alınan sulama suyu üretim değeri, birim sulama suyu ihtiyacına karşılık üretim değeri göstergelerinde yüksek performans göstermesi birinci sırada yer almasına yardımcı olmuştur. Sıralamada Korkuteli sulama şebekesinden sonra diğer sulama şebekeleri arasında ikinci olan Çıplaklı sulama şebekesi yer almaktadır. Bu sulama şebekesinin de özelliği tarımsal üretim göstergelerinin yüksek değer göstermesidir. $\mathrm{Bu}$ sonuçlar temel bileşenler analizi sonuçlarından elde edilmektedir. Birim sulanan alan üretim değeri, birim sulama alanı üretim değeri, birim şebekeye alınan sulama suyu üretim değeri göstergeleri ile sulama oranı, birim sulanan alana dağıtılan toplam sulama suyu miktarı, birim sulama alanına dağıtılan toplam sulama suyu miktarı, su temin oranı ve birim sulanan alana harcanan işletme-bakım masrafları arasında yüksek korelasyon bulunmaktadır. Bu nedenle kalite indeksine göre yapılan sıralamada sulama şebekelerine en çok etki eden üretim tarımsal erkinlik göstergelerin yanında su dağıtım performans göstergelerinin de geliştirilmesi başarı düzeyini arttıracaktır.

\section{Sonuç ve Öneriler}

Dünyada ve ülkemizde kit kaynakların en iyi şekilde değerlendirilmesi yapılan birçok çalışmanın kaynağını oluşturmaktadır. Suyun verimli kullanımı, elde edilen faydanın maksimum seviye çıkarılması sulama ile ilgili yapılan çalışmalar açısından son derece önemlidir. Yapılan çalışma kapsamında, Antalya bölgesinde bulunan sulama şebekelerinin başarısına en çok etki eden tarımsal etkinlik göstergelerinin olduğu görülmüştür. Bu göstergeler; birim sulanan alan üretin değeri, birim sulama alanı üretim değeri, birim şebekeye alınan sulama suyu üretim değeri, birim sulama suyu ihtiyacına karşılık üretim değeridir. Tarımsal etkinlik göstergelerini sulama performansının direkt olarak etkilediği göz önüne alındığında, üretim değeri yüksek ürünlerin yetiştirilmesi, birim alandan alınan ürünün arttırılmasına yönelik her türlü ilaçlama, gübreleme, kaliteli işçilik, tohum-fidan seçimi ve modern sulama yöntemleri ile su tasarrufu sağlanması gibi önlemlerin alınması gerektiği söylenebilir. Tarımsal etkinlik göstergeleri ile yüksek korelasyon gösteren su dağıtım performans göstergeleri de ikincil düzeyde sulama şebekeleri performansını arttırmaktadır. $\mathrm{Bu}$ nedenle, bölgede sulama şebekelerinin performansını arttırmada öncelik tarımsal etkinlik göstergeleri daha sonra su dağıtım performans göstergeleri olmalıdır.

\section{Teşekkür}

$\mathrm{Bu}$ çalışma, Kahramanmaraş Sütçü İmam Üniversitesinde yapılan "Sulama Şebeke Performanslarının Çok Değişkenli Bazı İstatistiksel Yöntemlerle Değerlendirilmesi: Türkiye Örneği” başlıklı tezden üretilmiştir.

\section{Kaynaklar}

Abera A, Verhoest NEC, Tilahun SA, Alamirew T, Adgo E, Moges MM, Nyssen F (2018) Performance of small-scale irrigation schemes in Lake Tana Basin of Ethiopia: technical and sociopolitical attributes. Physical Geography 40(3): 227-251.

Akkuzu E, Mengü GP (2012) Aşağı Gediz Havzası sulama birliklerinde karşılaştırmalı performans göstergeleri ile sulama sistem performansının değerlendirilmesi. Ege Üniversitesi Ziraat Fakültesi Dergisi 49(2):149-158.

Alpar R (2017) Çok değiş̧kenli istatistiksel yöntemler. Detay Yayıncılık, s. 42.

Arslan F, Değirmenci F (2017) Rating of some irrigation projects operated by DSI in Turkey. International Advanced Researches \& Engineering Congress, Osmaniye/TURKEY.

Arslan F, Değirmenci H (2018) Sulama şebekelerinin işletme-bakım ve yönetim modernizasyonunda RAP-MASSCOTE yaklaşımı: Kahramanmaraş sol sahil sulama şebekesi örneği. Atatürk Üniversitesi Ziraat Fakültesi Dergisi 49(1): 45-51.

Bareng JLR, Balderama OF, Alejo LA (2015) Analysis of irrigation systems employing comparative performance indicators: A benchmark study for national irrigation and communal irrigation systems in Cagayan River Basin. Journal of Agricultural Science and Technology A 5: 325-335. 
Bulut İ, Çakmak B (2001) Mersin bahçeleri sulamasında devir öncesi ve devir sonrası sistem performansının karşılaştırılması. Anakara Üniversitesi Ziraat Fakültesi Tarım bilimleri Dergisi (7): 58-65.

Çakmak B (2001) Konya sulama birliklerinde sulama performansının değerlendirilmesi. Tarım Bilimleri Dergisi 7(3): 111-117.

Córcoles JI, Tarjuelo JM, Moreno MA, Ortega JF, De Juan JA (2010) Evaluation of irrigation systems by using benchmarking techniques. XVIIth World Congress of the International Commission of Agricultural and Biosystems Engineering (CIGR) Hosted by the Canadian Society for Bioengineering (CSBE/SCGAB) Québec City, Canada.

Değirmenci H, Tanriverdi Ç (2016) Assessment of large scale irrigation schemes using irrigation intensity indicator in Turkey. In VII International Scientific Agriculture Symposium, "Agrosym 2016", Jahorina, Bosnia and Herzegovina, Proceedings, pp. 1961-1967.

Değirmenci H, Tanrıverdi Ç, Arslan F (2017) Aşağı Seyhan Ovası sulama birliklerinin kümeleme analizi ile karșılaştırılması. Kahramanmaraş Sütçü İmam Üniversitesi Tarım ve Doğa Bilimleri Dergisi 20(4): 326-333.

Eliçabuk C, Topak R (2017) Gevrekli sulama birliği'nde sulama performansının değerlendirilmesi. Selçuk Tarım Bilimleri Dergisi 3(2): 191-199.

Kartal S, Arslan F, Değirmenci H (2019) Assessment of Boğaçay, Çamgazi and Sarayköy irrigation schemes by statistical methods. Black Sea Journal of Agriculture 2(1): 27-34.

Kırnak H, Karaca L (2017) Sarığlan sulama birliği sahasında sulama performansının değerlendirilmesi. Gaziosmanpaşa Bilimsel Araştırma Dergisi 6 (BSM-2017): 35-41.
Kuscu H, Bölüktepe FE, Demir AO (2009) Performance assessment for irrigation water management: A case study in the Karacabey irrigation scheme in Turkey. African Journal of Agricultural Research 4(2): 124-132.

Malano H, Burton M, Makin I (2004) Benchmarkıng performance in the irrigation and drainage sector: A Tool for change. Irrigation and Drainage 53: 119-133.

Molden DJ, Sakthivadivel R, Perry CJ, Fraiture CD, Kloezen WH (1998) Indicators for comparing performance of irrigated agricultural systems. IWMI, Research Report 20, Colombo, p. 26.

Özdamar K (2015) Paket programlar ile istatistiksel veri analizi (çok değişkenli analizler). Nisan Kitabevi, Eskişehir.

Rao PS (1993) Review of selected literature on indicators of irrigation performance. International Irrigation management institute, IIMI research paper no: 13, Colombo, Sri Lanka.

Rodriguez-Diaz JA, Camacho-Poyato E, Lopez-Luque R, PérezUrrestarazu L (2008) Benchmarking and multivariate data analysis techniques for improving the efficiency of irrigation districts: An application in Spain. Agricultural systems 96(1-3): 250-259.

Svendsen M, Murray-Rust DH (2001) Creating and colsunting locally managen irrigation in Turkey: The Notional Perspective. Irrigation and Drainage Systems 15: 355-371.

Zema DA, Nicotra A, Tamburino V, Zimbone SM (2015) Performance assessment of collective irrigation in water users' associations of Calabria (Southern Italy). Irrigation and Drainage 64(3): 314-325. 